\title{
Stability of calcia-stabilized zirconia in fluoride molten salts under different voltage
}

\author{
Pan WANG, Cheng ZHANG, Jinfeng XIA, ${ }^{*}$ Tao FENG, ${ }^{*}$ Danyu JIANG* and Hongqiang NIAN*, ${ }^{*}$
}

Shanghai Institute of Technology, 201400, Shanghai, China

*Shanghai Institute of Ceramic, Chinese Academy of Sciences, Shanghai, China

\begin{abstract}
Rare metals could be produced by using a partially stabilized zirconia (PSZ) solid oxide membrane (SOM). The SOM membrane has to expose to a complex fluoride or chloride flux at high temperature. Besides, the SOM membrance was also affected by the loading voltage. In this work, we discussed the corrosion behavior of Calcia-stabilized zirconia (CSZ) in NaF-KF molten salts with different voltage. The results showed that CSZ tubes were eroded in experiments under different temperatures and voltages. This could be attributed to Ca dissolve out from the CSZ matrix, leading metastable tetragonal phase transfer to monoclinic phase. The corrosion rates of exposed to molten and the influence of voltage were also studied, and it was shown that the grain boundaries on the surface were mostly damaged after only $1 \mathrm{~h}$ corrosion. However, the CSZ tube could work in molten salts at least 50h. The effect of loading voltage, which could greatly enhance the corrosion behavior, was also studied. The corrosion mechanism of CSZ with different condition was discussed combining microstructures of surface and cross section, EDS and XRD analysis. Based on this work, we could determine the service life of the CSZ tubes and the voltage used in the produced process of rare metals.
\end{abstract}

(C2015 The Ceramic Society of Japan. All rights reserved.

Key-words : Calcia-stabilized zirconia, Solid oxide membrane, Molten salt corrosion

[Received October 1, 2014; Accepted February 7, 2015]

\section{Introduction}

Rare metals are absolutely necessary in the made of the precision guided, radar and a variety of weapons, and also are used as the compositions of alloy or equipment used in metallurgy, machinery and new materials. So it has important meaning to investigate and exploit the measures of preparation rare metals, which are lower cost, short flow and friendly to circumstance. Many researchers have done much work ${ }^{1-6)}$ until Fray, Chen etc, who are researchers of Cambridge University, presented FFC process in 2000. ${ }^{7-9)}$ It is a low energy consumption, short time and clean process, and has been used for the preparation of many metals and alloys. ${ }^{10)-15)}$ But there are some problems about this method: the electrolysis voltage should be controlled exactly in the process of electrolysis to avoid molten salt medium be electrolyzed that will reduce efficiency of the current and increase the times of electrolysis. Graphite anode rod was easily burned and reduced the whole reaction process stability. The solid oxide membrane (SOM) process has great potential to produce pure high value metals directly from their oxides at low cost and in an environmental friendly fashion. ${ }^{16), 17)}$ Previously, efficient production of various metals (e.g. magnesium, tantalum, titanium, ytterbium, silicon) has been demonstrated by the SOM process. ${ }^{18)-21)}$ The solid oxide membrane (SOM) process is actually the combination of the molten salt electrolysis and thermal reduction process, used both the oxygen transmission characteristics of SOM process and the advantage of FFC process. The oxide dissociated on the cathode which was protected by SOM from the fused salt, so that the oxygen diffuse through the solid oxide conducting membrane (referred to interchangeably as "SOM tube") to the anode, on which they were oxidized by losing electrons and converted to pure oxygen gas.

\footnotetext{
Corresponding author: H. Nian; E-mail: hqnian@mail.sic.ac.cn
}

Due to its excellent mechanical properties, zirconia has become an important structural ceramic. On the other hand, as a solidelectrolyte material, it leads to the attention by numerous researchers in the world. But the oxygen-ion conductivity of pure zirconia ceramic is very low, so stabilizing oxides such as $\mathrm{CaO}$, $\mathrm{MgO}, \mathrm{Y}_{2} \mathrm{O}_{3}$ or $\mathrm{Ce}_{2} \mathrm{O}_{3}$ are used for alloying pure zirconia to increase the oxygen-ion conductivity. ${ }^{22)}$ One of the main problems in this structure was the progressive spontaneous transformation of zirconia from the metastable tetragonal phase into monoclinic when it was attacked by molten salts. Additionally, during this transformation, volume increase apparently in the zirconia and the stress was produced when cooling from the firing temperature that could sufficiently crack the CSZ. ${ }^{23)}$ This phenomenon could damage the SOM and influenced the oxygen-ion conductivity of its. To understand the cause of CSZ degradation and subsequently develop strategies to improve membrane stability, we designed the molten salt corrosion experiments under electric field.

\section{Experimental}

\subsection{Sample preparation}

Fine CSZ powder with $3.8 \mathrm{wt} \% \mathrm{CaO}$ manufactured by our laboratory was used as raw material. After grinding, the powders were placed into a mould and isotropic pressed under $120 \mathrm{MPa}$ to form tube green body. And then the tubes were sintered at 1700 $1850^{\circ} \mathrm{C}$ for $2 \mathrm{~h}$, at a constant heating rate of $2^{\circ} \mathrm{C} / \mathrm{min}$. After cooling down to room temperature, the $\mathrm{CSZ}$ tube was received. The XRD result showed that there were $\mathrm{T}-\mathrm{ZrO}_{2}$ and $\mathrm{M}-\mathrm{ZrO}_{2}$ in the tubes.

In this study, mixed fluoride salts with mole ratio of $\mathrm{NaF}: \mathrm{KF}=$ 0.397:0.603 were used as corrosion medium to study the degradation and phase changes mechanism. The powders with the certain molar ratio were mixed, and then placed in ceramic crucibles. Before experiment, the powders were heated at $700^{\circ} \mathrm{C}$ for $2 \mathrm{~h}$ with a rate of $2^{\circ} \mathrm{C} / \mathrm{min}$ to remove crystal water. 


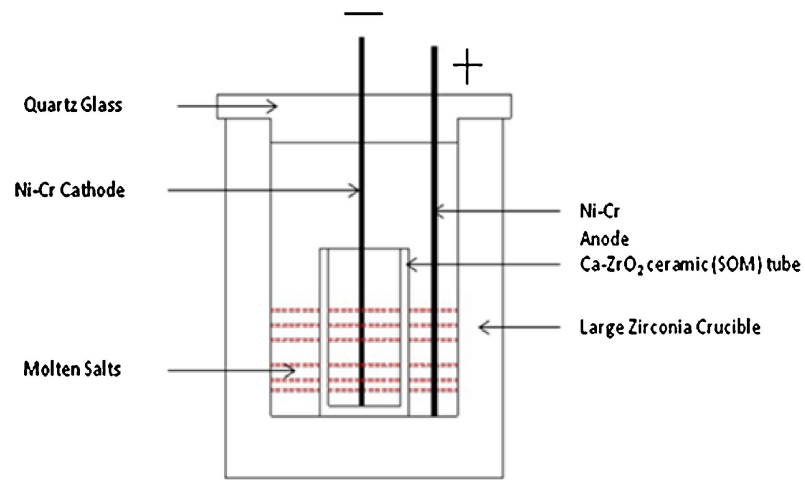

Fig. 1. Sketch-map of the corrosion process.

\subsection{Corrosion test}

Firstly, we discussed the static corrosion behavior of CSZ in fluoride molten salts using $10 \times 10 \times 4 \mathrm{~mm}$ pieces which were prepared with same technology as CSZ tubes. Before corrosion tests, the as-prepared CSZ pallets were grinded, polished and washed. After that, the pieces were totally dried under $80^{\circ} \mathrm{C}$. Three pieces covered by $20 \mathrm{~g}$ mixed salts were placed in ceramic crucibles and heated at $800^{\circ} \mathrm{C}$ for $2,4,6,8,10$ and $50 \mathrm{~h}$, respectively, with a rate of $2^{\circ} \mathrm{C} / \mathrm{min}$. After corrosion experiments, the pieces were completely washed, dried and analyzed.

The molten salt corrosion experiments process under electric field was shown in Fig. 1. The SOM tubes and large zirconia crucible were all full with mixed salts and heated to $800^{\circ} \mathrm{C}$ with different time and loading voltage.

\subsection{Characterization}

After hot corrosion testing, the samples were completely washed with deionized water and totally dried. X-ray diffraction analysis was performed to identify the corrosion products. The morphologies of surfaces and cross sections of samples, as well as the average grain sizes after experiment were characterized by scanning electron microscope equipped with an energy dispersive X-ray spectroscopy (EDS). The density of the sintered bodies was measured by the Archimedes method.

\section{Results}

Firstly, the XRD analysis was performed to figure out the component change of samples after corrosion experiments, and the results were showed in Fig. 2. It can be seen that there are both tetragonal $(\mathrm{T})$ and monoclinic $(\mathrm{M})$ phases in the as-prepared sample. Corroding to the diffraction intensities of two phases, the volume content of $\mathrm{T}-\mathrm{ZrO}_{2}$ was calculated and the value was $77.09 \%$. After corrosion test in fluoride molten salts for $2 \mathrm{~h}$ at $800^{\circ} \mathrm{C}$, the diffraction intensities of $\mathrm{T}-\mathrm{ZrO}_{2}$ was clearly decreased and the volume content was $1.18 \%$, while the diffraction intensities of $\mathrm{M}-\mathrm{ZrO}_{2}$ was increased and its volume content was $98.82 \%$. This revealed that phase transition was occurred on the sample surface and $\mathrm{T}-\mathrm{ZrO}_{2}$ changed to $\mathrm{M}-\mathrm{ZrO}_{2}$. Generally, the phase transition cannot happen at $800^{\circ} \mathrm{C}$. In this work, the phase transition was obvious which could be attributed the effect of molten salts.

To reveal the changes of element component, the energy disperse spectroscopy (EDS) was applied. The results showed that the $\mathrm{Ca}$ content was much lower compared with ceramic matrix. So we thought that during the corrosion test $\mathrm{Ca}$ was gradually dissolved from the ceramic surface, which reduced the phase stability of $\mathrm{T}-\mathrm{ZrO}_{2}$. When the $\mathrm{Ca}$ loses enough, then the phase transition occurred.

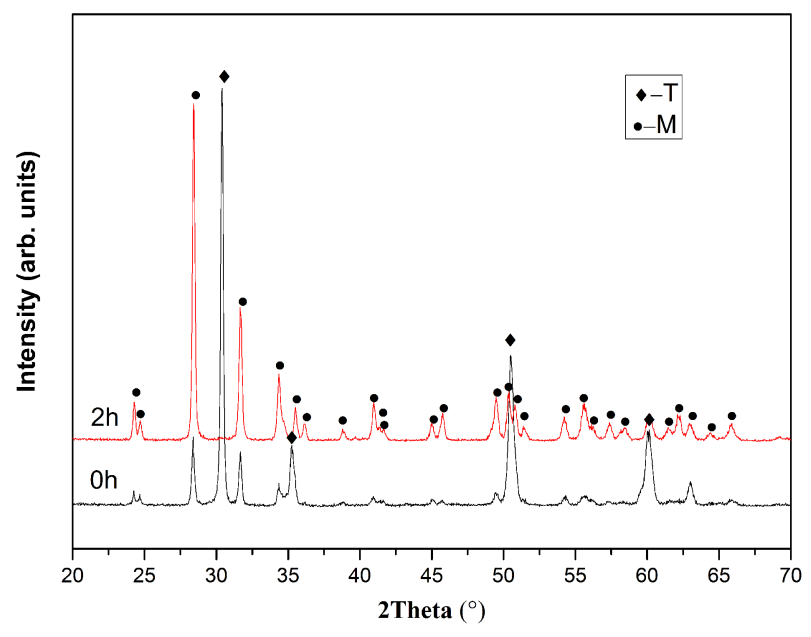

Fig. 2. XRD patterns of sample before and after corrosion test for $2 \mathrm{~h}$ in fluoride molten salts.
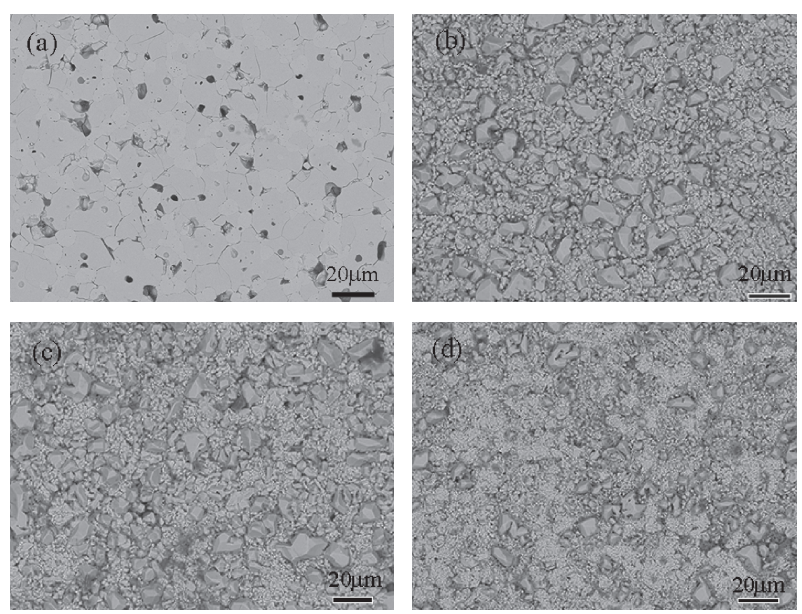

Fig. 3. Surface morphologies of samples after corrosion tests at the temperature of $800^{\circ} \mathrm{C}$ with different time: (a) $0 \mathrm{~h}$, (b) $2 \mathrm{~h}$, (c) $6 \mathrm{~h}$, (d) $10 \mathrm{~h}$.

Figure 3 showed the SEM micrographs of CSZ samples before and after corrosion tests in fluoride molten salts for 0 $10 \mathrm{~h}$. Figure 3(a) showed the surface morphology of the original sample. It could be seen that the grain size was around $8 \mu \mathrm{m}$. However, there was a few of grains showing 2-4 times bigger than the others. Figure 3(b) showed the surfaces of the samples after corrosion test for $2 \mathrm{~h}$ at $800^{\circ} \mathrm{C}$. The figure displayed that the grain boundaries were almost destroyed. There were lots of remarkable big grains about $6 \mu \mathrm{m}$ with some relatively smaller grains around the big ones. With the increasing of corrosion time, the amount of small grains also increased, and the big grains gradually cracked. After $10 \mathrm{~h}$ test, most big grains were broken to pieces and the surface exhibited irregular morphology. Combining with XRD results, with increasing of corrosion time, $\mathrm{Ca}$ was gradually dissolved and enhanced the phase transition of $\mathrm{T}-\mathrm{ZrO}_{2}$ to $\mathrm{M}-\mathrm{ZrO}_{2}$. As we know, there was volume change between T$\mathrm{ZrO}_{2}$ to $\mathrm{M}-\mathrm{ZrO}_{2}$. When the phase transition occurred, the stress caused by volume change could be enhancing the corrosion behavior. It also could be seen that slight flake off phenomenon exhibited in the corrosion area.

After molten salt corrosion tests, grain boundaries on the surface of ceramic were firstly attacked by fluoride molten salts. The phenomenon of grains broken was more and more clear. 
Besides, the small grains would separated from ceramic surface under the effects of tensile and shear stress. On the other hand, it was quite difficult that larger particles separated from the matrix because of the inner grain boundaries of the ceramic was too hard to be destroyed. The phenomena were showed in Fig. 3, and the lager grains were raised obviously. When the samples corroded by molten salts for $10 \mathrm{~h}$, the lager grains would be also broken to smaller grains under the effect of molten salts corrosion and phase-transition.

Figure 4 showed the cross-section of the sample after corrosion test in fluoride molten salt at $800^{\circ} \mathrm{C}$ for $6 \mathrm{~h}$. It could be seen that there was a clear layer which was formed by the grains which were smaller compared to matrix. Line scanning analysis was chosen to reveal the component distribution along the cross direction. It could be seen that $\mathrm{Ca}$ element fast diffused into the molten salt around grains, which enhanced the phase transition of $\mathrm{T}-\mathrm{ZrO}_{2}$ to $\mathrm{M}-\mathrm{ZrO}$. The $\mathrm{Ca}$ content is about $2.0 \%$ before the corrosion by the analysis of EDS, in the corrosion layer the $\mathrm{Ca}$ content is zero. Figure 4(b) told us a fact that the content of $\mathrm{Ca}$ in the corrosion layer is do less of the content in CSZ bulk and the rate controlling step of $\mathrm{Ca}$ out-diffusion from the tetragonal CSZ bulk to the surrounding molten salts at the grain boundary is relatively faster. Figure 4(c) told us that with the increasing of the corrosion time, the thickness of corrosion layer increased slowly.

Table 1 showed the weight loss of the samples after corrosion tests with different corrosion time. The weight loss of the samples when the voltage is zero, was received by $\Delta M=\left(M_{1}-M_{2}\right) / S$, in which $M_{1}$ and $M_{2}$ were the weights of sample before and after corrosion test and $\mathrm{S}$ was the area of the sample before the corrosion test. When the voltage was $1.5 \mathrm{~V}$, the both sides of tube sample were corroded. It was hard to describe the exact situation of both sides by direct measuring the weight change. So the weight loss was evaluated by thickness change. For compared, the weight loss was also received by $\Delta \mathrm{M}=\left(\mathrm{H}_{1}-\mathrm{H}_{2}\right) / 2 * \mathrm{~S}^{*} \rho$, in which $\mathrm{H}_{1}$ and $\mathrm{H}_{2}$ were the diameters of the samples before and after the corrosion, $\mathrm{S}$ was the unit area $\left(\mathrm{S}=1.0 \mathrm{~cm}^{2}\right)$ and $\rho$ was the density of the samples $\left(\rho=5.3 \mathrm{~g} / \mathrm{cm}^{3}\right) . \mathrm{H}_{1}$ and $\mathrm{H}_{2}$ were both measured by vernier caliper and the analysis precision was 0.01 $\mathrm{mm}$. It can be seen that CSZ showed relatively good corrosion resistance in fluoride molten salt. When the corrode time was short, the weight increased. This was all because that the molten salts would diffuse into the matrix through the cracks and the grain boundaries inside of the sample. But with the increase of corrosion time, the cracked grains will fall into the molten salts, and make the weight of CSZ decrease. The unsteadiness of the grain's fall off and the inevitable differences of the different samples make the up and down of the weight loss. However, when the corrode time was extended to $50 \mathrm{~h}$, the weight of the samples was reduced, which means the increase of fall off CSZ grains.

The grains of the tube before molten salt corrosion under electric field were polyhedron which was crystal size and good adhesion. In order to study the corrosion process under electric field and its corrosion mechanism, the cross-sections of samples after corrosion for $1 \mathrm{~h}$ in NaF-KF fluoride molten salts at $800^{\circ} \mathrm{C}$ under $1.5 \mathrm{~V}$ loading voltages were systematic investigated. Figure 5 showed the microstructures of cross-sections near the bottom of the sample about $5 \mathrm{~mm}$. The grain boundary in the outside area of corrosion layer is destroyed, and the bigger grains are broken up into some little ones, while in the inside area of corrosion layer, the grains are intact although its grain boundary is broken down.
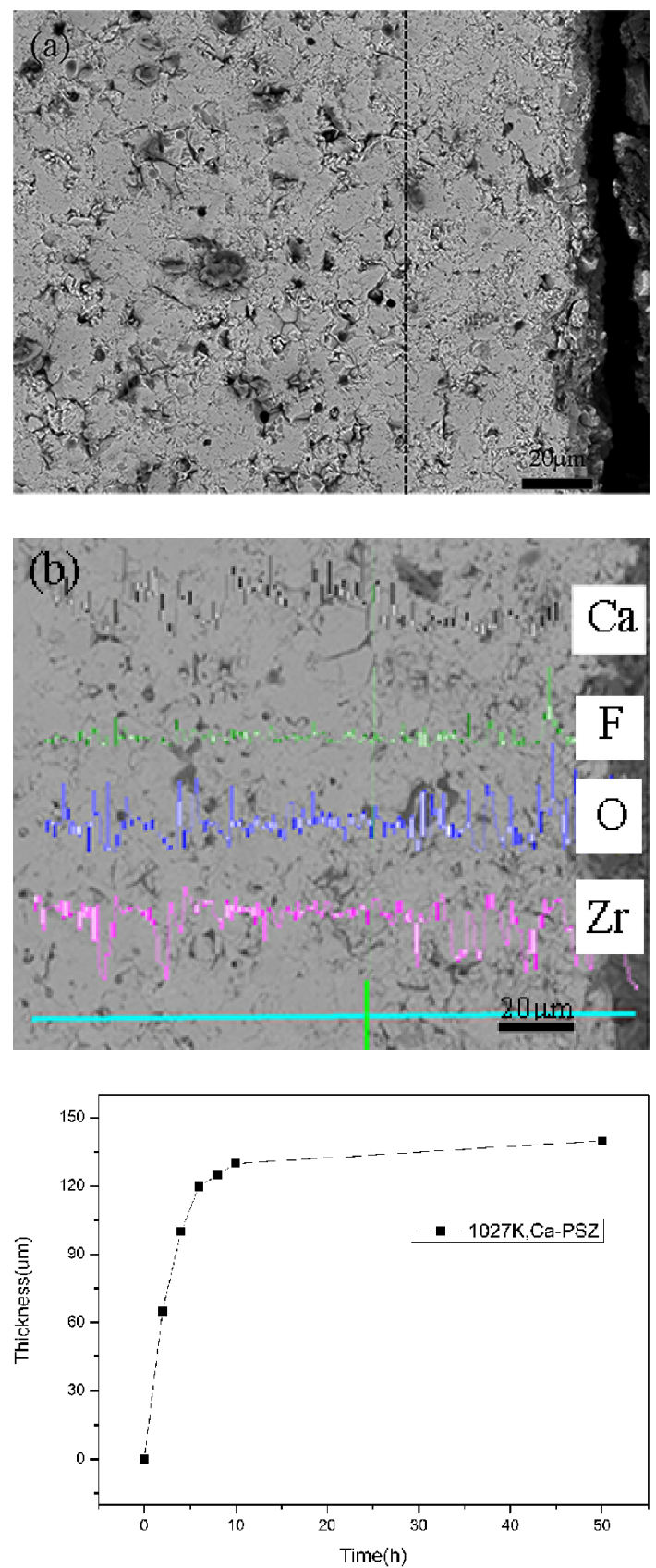

Fig. 4. (a) cross section of CSZ ceramic after corrosion test for $6 \mathrm{~h}$, (b) element distribution along the cross section in the corrosion layer, (c) corrosion layer thickness vs. corrosion time.

Table 1. Weight loss ratio of samples after corrosion test with different corrosion time

\begin{tabular}{rrrcccc}
\hline & $\begin{array}{c}2 \mathrm{~h} \\
\left(\mathrm{mg} / \mathrm{cm}^{2}\right)\end{array}$ & $\begin{array}{c}4 \mathrm{~h} \\
\left(\mathrm{mg} / \mathrm{cm}^{2}\right)\end{array}$ & $\begin{array}{c}6 \mathrm{~h} \\
\left(\mathrm{mg} / \mathrm{cm}^{2}\right)\end{array}$ & $\begin{array}{c}8 \mathrm{~h} \\
\left(\mathrm{mg} / \mathrm{cm}^{2}\right)\end{array}$ & $\begin{array}{c}10 \mathrm{~h} \\
\left(\mathrm{mg} / \mathrm{cm}^{2}\right)\end{array}$ & $\begin{array}{c}50 \mathrm{~h} \\
\left(\mathrm{mg} / \mathrm{cm}^{2}\right)\end{array}$ \\
\hline $0 \mathrm{~V}$ & -43.0 & -8.0 & -27.0 & -1.0 & -9.0 & 6.0 \\
$1.5 \mathrm{~V}-$ & 105.8 & 158.7 & 158.7 & $/$ & $/$ & $/$ \\
$1.5 \mathrm{~V}+$ & 52.9 & 52.9 & 105.8 & $/$ & $/$ & $/$ \\
\hline
\end{tabular}

Figure 6(a) told us that the thickness of anode side of the etch layer is increased firstly with the etching time increased, but it reduces when etching time is $4 \mathrm{~h}$ under $1.5 \mathrm{~V}$ working voltages, as well as $2 \mathrm{~V}$, which is because the corrosion layer fall off. The distribution of the etch layer became inhomogeneous gradually 

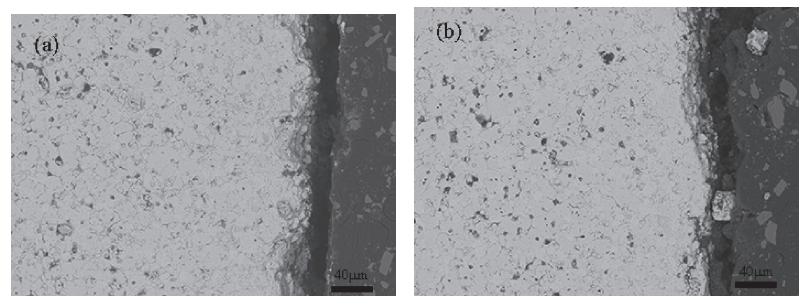

Fig. 5. microstructures of cross section of $\mathrm{Ca}-\mathrm{ZrO}_{2}$ ceramic after corrosion tests for $1 \mathrm{~h}$ at $800^{\circ} \mathrm{C}$ under $1.5 \mathrm{~V}$ loading voltage. (a) were the interior of the tubes which was close to cathode and (b) were the external of the tubes which was close to anode.

(a)
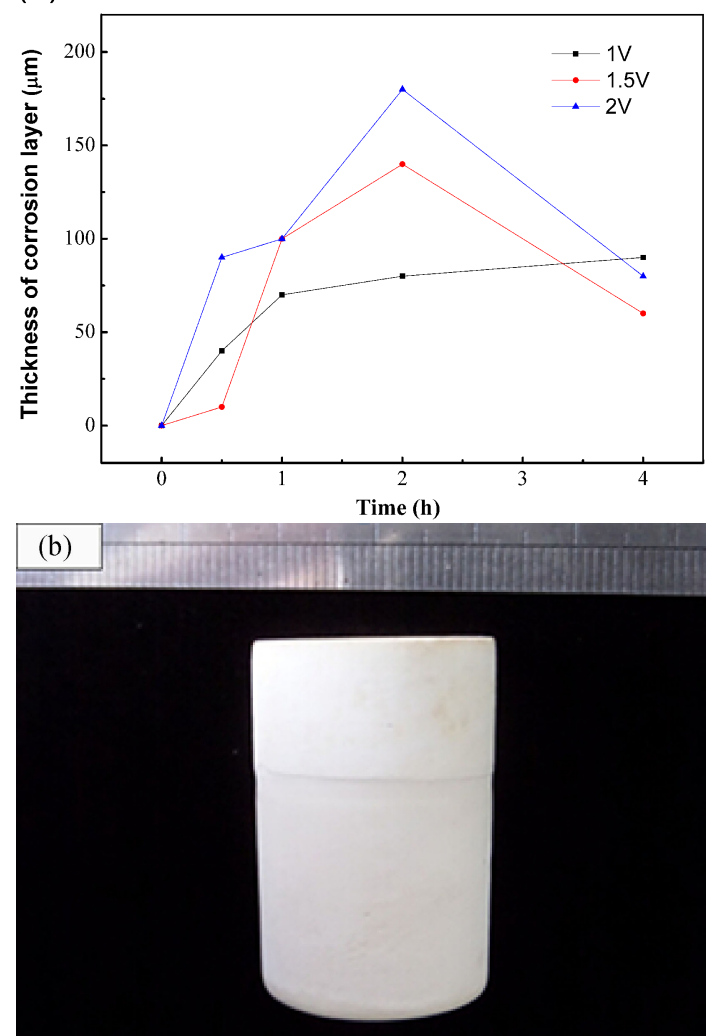

Fig. 6. (a) the thickness of the etch layer with different time, (b) macrostructure of SOM tube after corrosion test under electric field.

with the increase of the etching time. The macrostructure of the SOM tube after molten salt corrosion under electric field of $2 \mathrm{~V}$ for $6 \mathrm{~h}$ was shown in Fig. 6(b). When the outside of the CSZ tube is close to cathode, its reduction is $0.45 \mathrm{~mm}$, and it is $0.12 \mathrm{~mm}$ to anode at the corrosion tests under $2 \mathrm{~V}$ loading voltages and $800^{\circ} \mathrm{C}$, which told us that the reduction close to cathode is bigger contrast to close to anode.

After corrosion test for different time at $800^{\circ} \mathrm{C}$ under $2 \mathrm{~V}$, both outside and inside of ceramic tubes were obvious reduced. For example, the outside reduction was $0.45 \mathrm{~mm}$ after $6 \mathrm{~h}$ corroded at $800^{\circ} \mathrm{C}$ under $2 \mathrm{~V}$. When loading voltage decreased to $1.5 \mathrm{~V}$, the outside reduction was $0.03 \mathrm{~mm}$. However, there was almost no reduction after corrosion test for $2 \mathrm{~h}$ at $800^{\circ} \mathrm{C}$ under $1 \mathrm{~V}$ which means that the corrosion rate of CSZ was very small at low voltage. This was because the high external voltage would provide high energy to break the bonding of $\mathrm{Ca}-\mathrm{O}$ and $\mathrm{Ca}^{2+}$ would diffuse into the molten salts much quickly. All of those could promote the corrosion rate and phase transformation.

In order to research the relation of the CSZ solubility and its corrosion resistance in molten salts, we designed another test by adding $2 \mathrm{~g} \mathrm{CSZ}$ powder to the anode sides and the experiment voltage was $2 \mathrm{~V}$. After $6 \mathrm{~h}$ test, the thickness reduction of the tube near to anode was about $0.07 \mathrm{~mm}$, which was quite smaller compared to no CSZ powder adding. We thought that the addition of CSZ powder reduced the dissolution of $\mathrm{Ca}^{2+}$ in the tube and partly prevented the occurrence of phase transition, which enhanced the corrosion resistance of the CSZ tube.

The surface morphology after corrosion had been observed with SEM, where had a large numbers of regular grains on the surface only after the corrosion. Those grains were analyzed based on the semi-quantitative method of EDS measurement, especially $\mathrm{C}$ content. The result showed that the mass fraction of $\mathrm{C} / \mathrm{O} / \mathrm{F} / \mathrm{Na} / \mathrm{Ca}$ was $36.5 / 41.1 / 15.5 / 0.5 / 5.0$. Combined with $\mathrm{XRD}$ analysis, the large grains was considered as a mixture of $\mathrm{NaF}, \mathrm{CaF}_{2}$ and $\mathrm{CaCO}_{3}$. Besides, the $\mathrm{C}$ comes from $\mathrm{CO}_{2}$ in air and $\mathrm{CO}_{2}$ reacts with $\mathrm{Ca}^{2+}$ to produced $\mathrm{CaCO}_{3}$.

\section{Discussion}

\subsection{The mechanism of phase transformation and the corrosion process}

The changes on the surface of the samples after corrosion tested due to the phase transformation of CSZ. Pure $\mathrm{ZrO}_{2}$ exists three kinds of crystal lattices (Tetragonal, Cubic, Monoclinic), and the phase transformation of tetragonal to monoclinic phase occurs at about $950^{\circ} \mathrm{C}$ on cooling in pure $\mathrm{ZrO}_{2} \cdot{ }^{24)}$ By adding heterovalent cations, such as $\mathrm{Mg}^{2+}, \mathrm{Ca}^{2+}, \mathrm{Y}^{3+}$ to pure zirconia the tetragonal and cubic forms remain stable even at room temperature. ${ }^{24)}$ people reduces the martensite transformation staring temperature to a temperature below room temperature by add aliovalent oxides, such as $\mathrm{CaO}$, which reacts with $\mathrm{ZrO}_{2}$ increases the oxygen vacancy and $\mathrm{Ca}^{2+}$ will instead of $\mathrm{Zr}^{4+}$ in the $\mathrm{ZrO}_{2}$ lattice. ${ }^{7)}$

In the process of corrosion, the molten salt was around CSZ ceramic and gradually diffused into matrix. It was reported that $\mathrm{F}^{-}$anions in molten salts had much higher active ability compared with the inner diffusion ones, which would enhanced the corrosion behavior. ${ }^{16)}$ Under the effect of molten salts, $\mathrm{Ca}^{2+}$ cations diffused into the salts and the stabilizer became less and less, which caused the martensite transformation of $\mathrm{T}-\mathrm{ZrO}_{2}$ to $\mathrm{M}$ $\mathrm{ZrO}_{2}$. The tetragonal-to-monoclinic (T-M) phase transformation resulted in a volume swell, which further lead to compressive stress and shear strain. ${ }^{16)}$ All of this could bring lots of porosity and cracks. Those defects could enhance the corrosion behavior because the molten salt could penetrate into the CSZ ceramic matrix and corroded inside. The compressive stress increased with increasing of the distance from the surface. The existence of the compressive stress was disadvantageous to the tetragonal-tomonoclinic (T-M) phase transformation, ${ }^{24)}$ so the corrosion rate of the ceramic became slower with the extension of corrosion time.

Figure 7 was the proposed corrosion mechanism of membrane in molten salts at elevated temperature, which explained the changes of surface morphology, and the variation of corrosion layer. At first, the CSZ is around by molten salt, then the molten salt attracts grain boundary at the surface, and it permeates into the CSZ bulk through grain boundary just like the third picture. At the same time, the phase transformation of $\mathrm{T}$ to $\mathrm{M}$ happened at external of big grain and small grain, and the big grain broke up at the influence of shear strain. When the grain boundaries around a small grain are all damaged, it will fall off from the CSZ bulk and into the molten salt. 


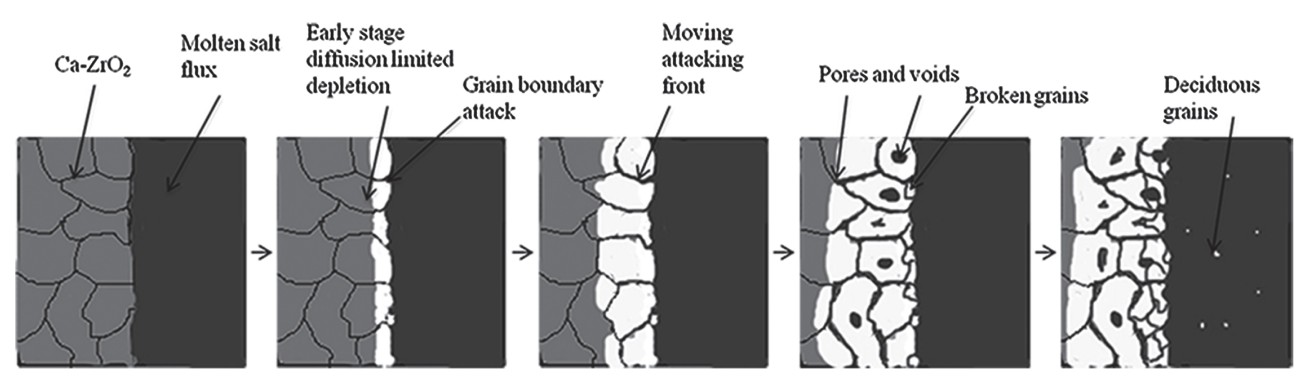

Fig. 7. Proposed corrosion mechanism of membrane in molten salt at elevated temperature.

\subsection{The comparison of cathode and anode corro- sion}

After the corrosion tests under electric field or not, the phenomenon of large particles split into some small particles were quite clear. The grains close to the corrosion layer were smaller than those inner the ceramic matrix. From the macrostructures of sample after corrosion tests, we knew corrosion layer outside could fall off from the tubes. However, the microstructures of cross sections figured out that the corrosion layer was not very thick. We thought that was because the corrosion rate was very large, and the corrosion layer containing damaged grains could fall off directly while the new surface was corroded quickly. We also compared the results of the cathode and anode sides of the tubes after corrosion test for $6 \mathrm{~h}$. The results showed that the cathode sides of the membrane were damaged more seriously than anode. This might be because the $\mathrm{Ca}^{2+}$ accumulates at anode sides and the $\mathrm{F}^{-}$aloof the cathode sides of the tubes, which was beneficial to the decrease of the corrosion rate. We have proved that the corrosion behavior had a direct relationship with the dissolution of $\mathrm{Ca}^{2+}$, and the react of $\mathrm{Ca}^{2+}$ with $\mathrm{F}^{-}$to $\mathrm{CaF}_{2}$. Thus, more $\mathrm{Ca}^{2+}$ and fewer $\mathrm{F}^{-}$would be beneficial to prevent the corrosion process.

\section{Conclusions}

A series of work we have did to understand the failure mechanism of CSZ and the influence of voltage to corrosion rate. The molten salts destroy firstly the CSZ through the grain boundary, the grain boundary attack leads to ingress of the flux into the attacked boundaries and defect and the out diffusion of $\mathrm{Ca}$ from the calcia-stabilized lattice to molten-salts in grain boundary, followed by the phase transformation, grain break up, volume expansion and particles fall off. The corrosion rate reduces with the increase of corrosion time, which is because the corrosion layer restricts partly the molten salt which permeates into the CSZ bulk. The ceramic disc of $4 \mathrm{~mm}$ thick could stand the test of at least $50 \mathrm{~h}$ under molten salts. The extra electric field will increase the corrosion rate, when the voltage is $1 \mathrm{~V}$ the influence of it is small, but when we increase the voltage to $2 \mathrm{~V}$, the CSZ tubes will be corroded quickly. The corrosion close to cathode is more serious contrast to close to anode. The whole work tells us that CSZ have good molten salts corrosion resistance, and it can be used as a SOM at a low decomposition voltage.

\section{References}

1) S. Wang and Y. Li, J. Electroanal. Chem., 571, 37-42 (2004).

2) D. J. Fray, Electrochemical processing using slags, fluxes and salts, VII International Conference on Molten Slags Fluxes and Salts. (2004) pp. 6-12.

3) R. O. Suzuki and K. Ono, Proceedings of the 13th International Symposium on Molten Salt, The Electrochemical Society, Penningston. 54(3) (2002) pp. 80-82.

4) R. O. Suzuki, J. Phys. Chem. Solids, 66, 461-465 (2005).

5) S. Guo, J. Peng, S. Zhang, L. Zhang and X. Fan, Chinese Journal of Rare Metals., 24, 1091-1094 (2004).

6) R. O. Suzuli and K. One, Proceedings of Yazawa International Symposium Metallurgical and Materials Procdsssing: Principles and Technologies, The Minerals soc. 23(2) (2003) pp. 1819.

7) D. J. Fray, T. W. Farthing and G. Z. Chen, Removal of oxygen from metal oxides and solid solution electrolysis in a fused salt, International Patent WO99/64638. (1999) pp. 21-22.

8) G. Z. Chen, D. J. Fray and T. W. Farthing, Nature, 40, 361-364 (2000).

9) S. Liu, Procedia Earth and Planetary Science, 2, 1-6 (2011).

10) X. Yan and D. Fray, J. Electrochem. Soc., 152, 12-21 (2005).

11) T. Nohira, K. Yasuda and Y. Ito, Nat. Mater., 2, 397-401 (2003).

12) X. Yan and D. Fray, J. Mater. Res., 18, 346-356 (2003).

13) G. Chen, E. Gordo and D. Fray, Mater. Trans., 35B, 223-233 (2004).

14) E. Gordo, G. Chen and D. Fray, Electrochim. Acta, 49, 21952208 (2004).

15) G. Chen, D. Fray and T. Farthing, Metall. Mater. Trans., 32B, 1041-1052 (2001).

16) J. Xu, B. Lo, Y. Jiang, U. Pal and S. Basu, J. Eur. Ceram. Soc., 34, 3887-3896 (2014).

17) U. Pal, JOM J Miner Metals Mater., 59, 44-49 (2007).

18) A. Krishnan, X. G. Lu and U. B. Pal, Metall. Mater. Trans., B, 36, 463-473 (2005).

19) A. Krishnan and X. Lu, Scand. J. Metall., 34, 293-301 (2005).

20) M. Suput, R. Delucas, S. Pati, G. Ye, U. Pal and A. C. I. V. Powell, Miner. Process. Extr. Metall., 117, 118-122 (2008).

21) Y. Jiang and P. Zink, ECS Trans., 41, 171-180 (2012).

22) C.-J. Ho and W.-H. Tuan, Ceram. Int., 37, 1401-1407 (2011).

23) G. Ergun, M. Gurub and F. Egilmez, Ann. Anat., http://www. sciencedirect.com/science/article/pii/S0940960214000181 (2014).

24) H. J. Richard, J. Am. Ceram. Soc., 83, 461-487 (2000). 